\title{
SÍNDROME DE SNEDDON
}

\author{
RELATO DE TRÊS CASOS
}

\section{VLADIMIR ARRUDA ZACCARIOTTI*, LUIZ FERNANDO MARTINS**, VALTER DA COSTA**, NILZIO A. DA SILVA***, ALBERTO A. LAS CASAS****, SEBASTIÄO EURICO DE MELO-SOUZA ****}

\begin{abstract}
RESUMO - Descrita por Sneddon (1965) a síndrome consiste na ocorrência de acidente vascular encefálico (AVE) isquêmico em pacientes com livedo reticular. Trata-se de doença vascular sistêmica de causa desconhecida, em que há comprometimento de artérias de médio e pequeno calibres. Pode haver positividade dos anticorpos antifosfolípides. São apresentados três casos desta cntidade, todos do sexo masculino com 7, 16 e 54 anos de idade. Em todos a instalação do quadro deu-se por convulsð̌es focais seguidas de hemiparesia ou paralisia labio-glossofaríngea. Os pacientes não tiveram outras manifestą̧ões neurológicas em 2 anos de acompanhamento. A investigaçăo laboratorial demonstrou presença de anticorpos antifosfolípides e anticardiolipina em 1 caso. A investigąão neuro-radiológica forneceu os seguintes resultados: TCC e RM com infarto nos 3 casos, e angiografia com obstruçăo de vasos de médio e pequeno calibre. A síndrome de Sneddon nāo parece ser tăo rara e deve fazer parte de protocolos de investigação de AVE, especialmente em grupos mais jovens.
\end{abstract}

PALAVRAS-CHAVE: síndrome de Sneddon, doença cerebrovascular, anticorpos antifosfolípides.

\section{Sneddon's syndrome: report of three cases}

SUMMARY - The Sneddon's syndrome consists of neurologic manifestations associated to the presence of livedo reticularis and cyanosis of the extremities. The pathological process is an endothelial obliteration of arterioles, leading to a reticular appearance of the skin, despite the environment temperature. The authors present three new cases, causasian males with 7,16 and 54 years of age. The youngest started with hemilateralized motor seizures and showed a porencefalic area in the CT scan. The oldest had livedo reticularis, acrocyanosis and started with hemilateralized motor seizures, and a hemiparesis as sequela; CT scan with parasagittal infarct and occlusion presented of one anterior cerebral artery on angiography. The third patient started with hemifacial seizures, developed a labioglossolaringeal paresis and dysarthria as sequela; CT scan and MRI showed multiple infarcts, with multiple occlusions of cortical branchs on angiography. The skin biopsies showed endothelial vascular hyperplasia in all cases. Only one (54 years old) patient had a positive IgG antiphospholipid antibodies. The Sneddon's syndrome seems not to be so rare and have to be considered in the etiological investigation of cerebral infarcts, mainly in young people.

KEY WORDS: Sneddon's syndrome, cerebrovascular disease, antiphospholipid antibodies.

Em 1960 Champion e Rook ${ }^{3}$ chamaram a atenção para a associação de livedo reticular e acidente vascular encefálico (AVE). Cinco anos apos, Sneddon ${ }^{18}$ descreveu 6 casos, sendo $5 \mathrm{em}$ mulheres $\mathrm{e} I \mathrm{em}$ homem, nos quais encontrou clara associação entre essas duas entidades. A partir dal surgiram vários relatos na literatura totalizando, em nossa revisão, 143 casos até o momento.

Instituto de Neurologia de Goiânia: *Médico Residente; **Neurocirurgiăo; ***Reumatologista; ****Cardiologista; ****Neurologista, Coordenador de Ensino e Pesquisa. Aceite: 9-agosto-1994. 
Apresentamos neste trabalho três casos diagnosticados no Instituto de Neurologia de Goiânia, no período de 1986 a 1991.

\section{CASUÍSTICA E MÉTODOS}

Foram estudados três pacientes todos do sexo masculino, com idade de 7,16 e 54 anos na época do diagnóstico. O diagnóstico foi determinado pela história clínica e exame físico, auxiliado por exames complementares laboratoriais, tomografia computadorizada do crânio (TCC), ressonância magnética (RM) do crânio e angiografia cerebral bilateral por cateterismo seletivo, que serão discutidos.

Tabela 1. Resultados dos exames complementares.

\begin{tabular}{lccc}
\hline & Caso 1 & Caso 2 & Caso 3 \\
\cline { 2 - 4 } Hemograma, TPT, TP, VHS & Normais & Normais & Normais \\
LCR, EAS & Normais & Normais & Normais \\
Latex, FAN, HBsAg, RSS & Normais & Normais & Normais \\
Anticorpos anticardiolipina & Posit. (IgG) & Negat. & Negat. \\
ECG & Normal & Normal & Normal \\
\hline
\end{tabular}

Resultado dos exames laboratoriais e eletrocardiograma dos 3 pacientes. TPT, tempo parcial de tromboplastina; TP, tempo de protombina; VHS, velocidade de hemossedimentação; LCR, líquido cefalorraquidiano; EAS, análise de sedimento urinário; Latex, prova do latex; FAN, fator anti-nuclear; HBsAg, antígeno Austrália; RSS, reaçōes sorológicas para sffilis; ECG, eletrocardiograma.

Tabela 2. Resultados dos exames neuro-radiológicos: tomografia computadorizada do cranio (TCC). ressonância magnética (RM) e angiografia cerebral (por cateterismo seletivo dos 4 vasos).

Casol. TCC: Infarto cerebral recente de substância branca profunda mesial fronto-pariental esquerda.

RM: não realizada.

Angiografia: Oclusão de artéria cerebral esquerda.

Caso 2. TCC e RM: Infartos cerebrais antigos nas regiớes fronto-temporal direita, pariento-occipital esquerda, têmporo-occipital esquerda $e$ infarto cerebral recente na região cơrtico-subcortical junto à fenda silviana esquerda (Fig 2 e 3).

Angiografia: Opacificaçāo arterial tardia dos ramos centrais de ambas as arterias cerebrais médias, assim como dos ramos parientais posteriores.

Caso 3. TCC: Infarto cerebral antigo na regiâo têmporo-pariental direita.

RM e Angiografia: não realizadas.

Tabela 3. Resultado do exame histopatológico dos três casos.

Biópsia de pele: Reação inflamatória discreta, acompanhada de hiperplasia endotelial em todos os casos.

Caso 1. JPO, 54 anos, masculino, branco. Há 6 meses vinha apresentando "problema de circulaçăo" manifestado por arroxeamento, extremidades frias e diminuição da força do lado direito (D). Há 1 dia da internaçāo apresentou crise convulsiva focal (D), com dificuldade para falar, sucedida por hemiparesia (D). No exame inicial havia hemiparesia (D) (75\%), Babinski à D, cianose de extremidades e livedo reticular (PA: 130x80). Nao havia alteraçðes do estado mental, cardiacas, pulmonares, gastro-intestinais ou renais. Foi intemado e realizados exames complementares (Tabelas $1,2 \mathrm{e} 3$ ). Medicado com anticoagulantes, antiagregante plaquetário e corticóide. Evoluiu bem, teve alta sem déficit neurológico e mantem-se estável sob observaçăo hă 3 anos.

Caso 2. VJMF, 16 anos, branco, masculino. Admitido em caráter de emergência em estado de mal convulsivo focal em hemiface D iniciado havia 24 horas. Apresentava sialorréia, disfagia e disartria, cianose de extremidades, aspecto rendilhado da pele compativel com livedo reticular (Fig 1). Coraçăo, pulmöes, trato 
Fig 1. Caso 2. Fotografia do flanco esquerdo mostrando aspecto rendilhando da pele (livedo reticular).

\section{RESULTADOS}

Em todos os casos a manifestação inicial se deu por crises convulsivas focais, sendo seguidas de hemiparesia (Caso 1) e paralisia labioglossofaríngea (Caso 2). 0 Caso 3 não apresentou deficit motor. Os exames laboratoriais demonstraram anticorpos antifosfolípides (anticardiolipina tipo IgG) no Caso 1. Estes anticorpos não foram encontrados nos outros 2 casos (Tabela 1). Realizada TCC em todos os casos e RM no Caso 2, sendo demonstrado tanto a presença de infartos cerebrais recentes (Casos 1 e 2), como antigos (Casos 2 e 3) (Fig 2 e 3). A angiografia cerebral por cateterismo seletivo foi realizada demonstrando oclusão da artéria cerebral anterior esquerda no Caso 1 e opacificação tardia nos ramos centrais de ambas as artérias cerebrais médias, assim como nos ramos parietais no Caso 2. compatível com lesão encontrada na TCC (Tabela 2). Para se confirmar o diagnóstico foi realizado estudo histopatológico de biopsia de pele com microscopia simples e coloração habitual, observando-se presença de hiperplasia gastro-intestinal e rins normais. História pregressa de súbita dificuldade para falar há 1 ano com regressão espontânea. Paralisia facial transitória há 3 meses, novamente comprometendo a fala, de involuçăo em horas. Há 6 dias da internação apresentou crise convulsiva focal em hemiface (D), de duraçāo breve. Foi internado, realizados exames complementares (Tabelas 1, 2 e 3). Evoluiu com melhora progressiva dos sinais neurologicos e sem crises convulsivas. Teve alta após $\mathbf{1 0}$ dias, com disartria moderada. Foi medicado com anticoagulante, anticonvulsivante, corticóide e bloqueador de canais de cálcio. Encontrase sob observaçāo há 6 anos, esporadicamente apresentando episodios de maior dificuldade para falar, todos com regressāo quase total, permanecendo disartria moderada até o momento atual.

Caso 3. EACN, 7 anos, branco, masculino. Apresentou historia de crise convulsiva focal esquerda pela primeira vez 1 dia antes da consulta. Ao exame não havia sinais neurologicos, apenas livedo reticular sem cianose de extremidades. Fez exames complementares (Tabelas 1, 2 e 3). Foi medicado com anticonvulsivante e corticoide. Acompanhado por 1 ano, apresentou 2 crises convulsivas, uma generalizada e outra focal esquerda. Não retomou a controle nos últimos 2 anos.

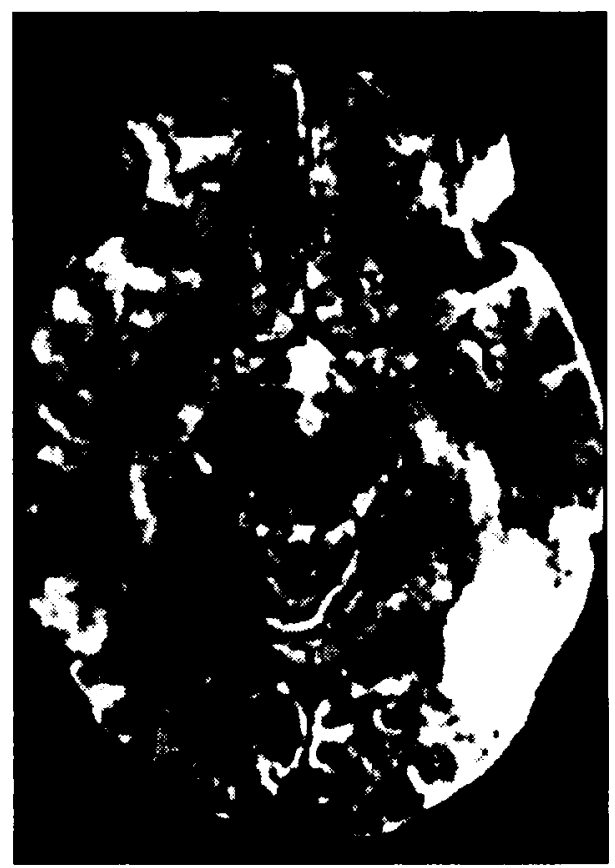

Fig 2. Caso 2. RM mostrando infarto cerebral antigo na regiāo têmporo-occipital esquerda. 


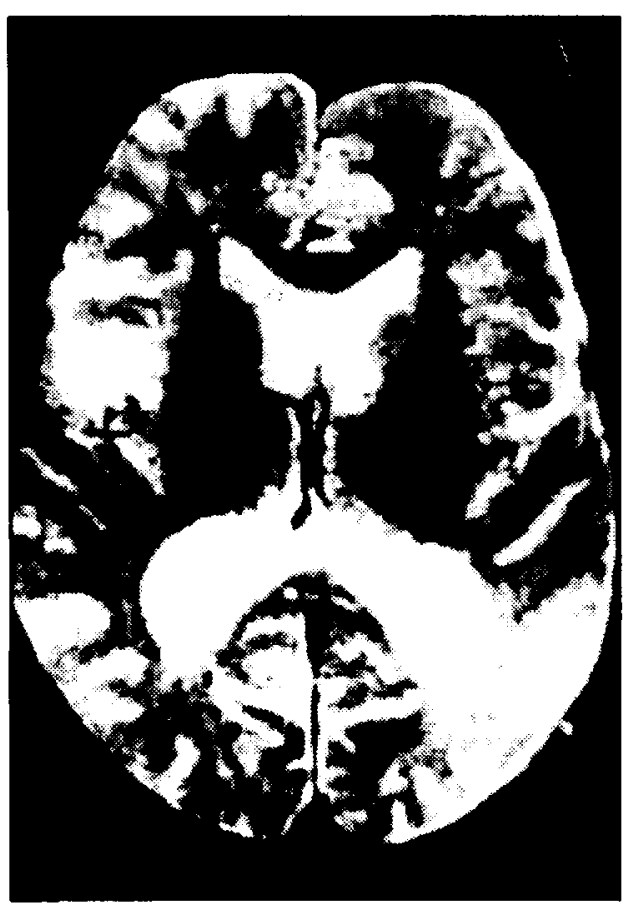

Fig 3. Caso 2. RM mostrando infarto cerebral antigo na regido parieto-occipital esquerda e infarto córticosubcortical junto a fenda silviana direita. endotelial de vasos de pequeno e médio calibre em todos os casos (Tabela 3).

\section{COMENTÁRIOS}

Os 3 casos apresentados se enquadram dentro da síndrome de Sneddon pelos achados do exame físico, história e comprovação laboratorial. Quando Sneddon's descreveu a ocorrência simultânea de livedo reticular e AVE, supôs que "poderia ser um tipo de endarterite obliterante similar a arteriopatia de Takayasu"; porém vários estudos posteriores comprovaram tratar-se de doença distinta e com características próprias 4.7.10.15,20. A síndrome é caracterizada pelo achado de AVE e livedo reticular. O livedo reticular, que na língua alemã é denominado livedo racemoso, é alteração de pele causada por distúrbio circulatório, dando o aspecto rendilhado e difuso. Ele ocorre por obliteração da luz do vaso, causando hipofluxo arterial na pele. Assim, o paciente aparenta o aspecto rendilhado irregular, localizado e persistente mesmo com variação da temperatura. As entidades que podem ser responsáveis são: oclusão aterosclerótica; vasculites; como componente da síndrome de Sneddon, como em nossos casos. Porém, pode também estar presente em pessoas normais, neste caso sendo transitório e altera-se com a mudança de temperatura da pele. $\mathbf{O}$ livedo reticular pode ocorrer juntamente ou precedendo o AVE em $55 \%$ dos $\operatorname{casos}^{19}$, bem como logo após a ocorrência do AVE. Em nossos casos o livedo precedeu o AVE (Caso 1 e 3) ou se deu ao mesmo tempo (Caso 2). A etiologia permanece obscura embora Rebollo ${ }^{15}$ proponha uma hipótese genética, que não chegou a ser confirmada por outros. Schulze-Lahoff e outros ${ }^{17}$ consideraram que complexos circulantes de IgM poderiam participar de patogênese da doença. Ellie e outros ${ }^{5}$ entendem que as gonadotrofinas que induzem ao hiperestrogenismo poderiam ser responsáveis principalmente nos casos em que anticorpos antifosfolípides não fossem encontrados. Recentemente, Kalashnikova e outros ${ }^{8}$ mostraram, em uma série de 46 pacientes, uma associação importante, da presença de anticorpos antifosfolípides em níveis elevados e sugerem ser fator importante para a gênese desta doença. Alguns anos atras, Levine ${ }^{10}$ propôs que esta entidade pudesse ser uma síndrome de anticorpos antifosfolípides já que em muitos casos estes anticorpos foram detectados. Porém foram publicadas algumas séries em que não se encontrou esta associação. Levine ${ }^{12}$ reviu sua hipótese inicial e propôs que a "síndrome de Sneddon seja realmente uma sindrome de causas variadas dentre as quais anticorpos antifosfolípides seria uma delas". A incidência da síndrome não é conhecida mas foi relatada em $0,26 \%$ dos casos de AVE em estudo de 3006 casos $^{15}$.

A maioria dos casos ocorre em mulheres, em até 7 por 1 em relaçăo aos homens, mas nossos casos foram todos do sexo masculino. $O$ início dos sintomas neurológicos varia, porém predomina em adulto jovem. Quanto às manifestaçōes clínicas associadas, a hipertensão arterial parece uma constante em alguns estudos ${ }^{8}$, o que não se repete em nossa série. Recentemente, Stockhammer e col. ${ }^{20}$ publicaram 17 casos, dos quais 14 apresentavam cefaléia e 8 vertigens como manifestações neurológicas iniciais, seguidas de ataques isquêmicos transitórios (AIT). 
Todos os nossos casos apresentaram crise convulsiva focal como a manifestação neurológica inicial. A maioria dos sintomas são decorrentes da obstrução dos vasos da circulação cerebral anterior, manifestado principalmente por hemiparesia, deficit hemi-sensorial ou comprometimento da fala, dependendo da predominância hemisférica. Essas manifestações tanto podem ocorrer como AIT ou como um infarto estabelecido. Além destas manifestações neurológicas, podemos encontrar ainda cefaléia, alteração da memória e coréia ${ }^{8}$. Clinicamente, outros problemas de ordem circulatória podem ocorrer como trombose venosa profunda, envolvimento do endocárdio, aborto espontâneo ou mesmo morte intra-uterina e hipertensão arterial sistêmica ${ }^{8}$, que não tivemos oportunidade de detectar em nossos pacientes.

Podemos encontrar trombocitopenia, velocidade de hemossedimentação elevada, alteração dos niveis de creatinina sérica ${ }^{20}$, bem como a ocorrência de anticorpos antifosfolípides.

Anticorpos antifosfolípides são aqueles que reagem cruzadamente com a cardiolipina e outros fosfolípides de carga negativa. $O$ mecanismo pelo qual são produzidos é desconhecido', podendo ser encontrados em pessoas normais (de 2 até $5 \%$ da população), em lupus eritematoso sistêmico, em esclerodermia, em doença de Behcet, em infecções e induzida por medicamentos (clorpromazina, procainamida, fenitorna, fansidar, hidralazina, quinidina, estreptomicina). As infecçōes e medicamentos geralmente induzem a produção de anticorpos antifosfolípides. Os mecanismos possíveis de causar a doença são o bloqueio de prostaciclina (PGI2) produzida pela parede dos vasos, diminuição da atividade da trombomodulina, inibição da ativação de proteínas $\mathrm{C}$, diminuição do plasminogênio tecidual e a inibição da pré-calicreina ${ }^{6,10}$. A presença de anticorpos antifosfolípides está relacionada a várias manifestaçð̃es como livedo e úlcera nas pernas, anemia hemolítica, valvulopatias, hipertensão arterial. As manifestações neurológicas principais são coréia, amaurose, demência, convulsões, enxaqueca, neuropatia ou sinndrome de Guillain-Barré. O diagnóstico de anticorpos antifosfolípides pode ser suspeitado pela positividade de reações sorológicas para sífilis, pelo prolongamento do tempo parcial de tromboplastina direta e pela identificação de anticardiolipina ou lupus anticoagulante. Em nossos casos a sorologia para sffilis foi sempre negativa, o tempo parcial de tromboplastina normal e anticorpos anticardiolipina estavam presentes apenas em 1 caso. Não foi feita pesquisa de lupus anticoagulante.

O método de imagem é de grande valor, tanto a angiografia quanto a TCC e a RM. A TCC, embora tenha menor sensibilidade que a RM é mais difundida em nosso meio e representa o método mais importante para visualização de infartos cerebrais. A angiografia cerebral deve ser realizada quando se pretende observar o estado das artérias e o local da obstrução com maior precisão. Muitas vezes há múltiplas oclusōes, principalmente nos ramos distais das artérias cerebrais. Ela pode ser normal em alguns casos. A angiografia realizada em dois dos nossos pacientes, demonstrou bloqueio proximal da artéria cerebral anterior (Caso 1) e bloqueio de ramos centrais da artéria cerebral média (Caso 2).

O diagnóstico, porém, só pode ser confirmado pela biopsia de pele com retirada de cone profundo e microscopia. Observa-se endotelite de pequenos vasos com proliferação celular subendotelial, levando a obstrução parcial ou completa dos vasos ${ }^{20}$. Em nossos 3 pacientes conseguimos comprovar o diagnóstico por este exame. $O$ diagnóstico diferencial deve incluir qualquer doença em que exista ocorrência simultânea de livedo reticular e envolvimento arterial sistêmico's, como aterosclerose, doenças com oclusão intravascular e vasculites.

\section{REFERENCIAS}

1. Brey RL, Hart RG, Sherman DG, Tegeles CH. Antiphospholipid antibodies and cerebral isquemia in young people. Neurology 1990, 40:1150-1196.

2. Burton TL. Livedo reticularis, porcelain, white scars, and cerebral thromboses. Lancet 1988 , 1:1263-1265. 
3. Champion R, Rook A. Livedo reticularis. Proc R Soc Med 1960, 53:961-962.

4. Cosmes A, Perroud AM, Mathieu A, Jourdain C, Touraine R. Livedo reticularis et accidents vasculaires cerebraux. Ann Dermatol Venereol 1986, 133:137-141.

5. Ellie E, Le Massa O, Julien J, Parneix I, Royer P, Beylot C. Gonadotrophins , livedo reticularis and stroke. Stroke 1190, 21:1377-1378.

6. Harris EN, Gharavi AE, Hughes GRY. Antiphospholipid antibodies. Clin Rheum Dis 1985, 11:591-609.

7. Kalashnikova CA, Asonde EL, Kushekbaeva AE, Graceva LA. Anticardiolipine antibodies in Sneddon's syndrome. Neurology 1990, 40:464-467.

8. Kalashnikova LA, Nasonov EL, Sotyanovich LZ, Kovalyov VU, Kosheleva NM, Reshetnysk TM. Sneddon's syndrome and the primary antiphospholipid syndrome. Cerebrovasc Dis 1994, 4:76-82.

9. Levine SR, Deegan MJ, Eutrell N, Welch KMA. Cerebrovascular and neurologic disease associated with antiphospholipid antibodies: 48 cases. Neurology 1990, 40:1181-1189.

10. Levine SR, Langer SL, Albers JW, Welch KMA. Sneddon's syndrome: an antiphospholipid antibody syndrome. Neurology 1988, 38:798-800.

11. Levine SR, Welch KMA. The spectrum of neurologic disorders associated with antiphospholipid antibodies: lupus anticoagulants and anticardiolipin antibodies. Arch Neurol 1987, 44:876-883.

12. Levine SR, Welch KMA, Langer SL, Albers WJ. Sneddon's syndrome (letter). Neurology 1989, 39:1138-1139.

13. Montalbon J, Ordi J, Barquinero J, Vilardell M. Sneddon's syndrome and anticardiolipine antibodies (letter). Stroke 1988, 19:785-786.

14. Routenberg W, Hennerici M, Aulich A, Holzke E, Zakomek HJ. Immunosuppressive therapy and Sneddon's syndrome. Lancet 1988, 2:629-630.

15. Rebollo M, Val JF, Garijo F, Quintana F, Berciano F. Livedo reticularis and cerebrovascular lesions (Sneddon's syndrome). Brain 1983, 106:965-979.

16. Rumpl E, Nechofer T, Pallus A, Willeit A, Vogl G, Stamplet G, Platz T.H. Cerebrovascular lesions and livedo reticularis (Sneddon's syndrome): a progressive cerebrovascular disorder? J. Neurol 1985 , 231:324-330.

17. Schulze-Lahoff E, Kespl F, Bleil L, Burnester GR, Kolble K, Nublein HG, Rodl W, Kalden JR. IGM containg immune complexes and antiphospholipid antibodies in patients with Sneddon's syndrome. Rheumatol Int 1989, 9:43-48.

18. Sneddon JB. Cerebrovascular lesions and livedo reticularis. Br J Dermatol 1965, 77:180-185.

19. Stephens WP, Ferguson JT. Livedo reticularis and cerebrovascular disease. Postgrad Med J 1982, 58:70-73.

20. Stockhammer G, Felber SR, Zelger B, Sepp N, Bisbsner GG, Frithch PO, Aichner FT. Sneddon's syndrome: diagnosis by skin biopsy and MRI in 17 patients. Stroke 1993, 24:685-690. 